\title{
Reaching blood pressure guideline targets with the CNIC polypill in patients with a previous cardiovascular event in Mexico: a post hoc analysis of the SORS study
}

\author{
Enrique Gómez-Álvarez ${ }^{1}$, Juan Verdejo ${ }^{2}$, Salvador Ocampo ${ }^{3}$, Emilio Ruiz*,4 \& Marco A \\ Martinez-Rios ${ }^{2}$, On behalf of the SORS investigators \\ ${ }^{1}$ Centro Médico Nacional 20 de noviembre, ISSSTE, México \\ ${ }^{2}$ Instituto de Nacional de Cardiología Ignacio Chávez, Ciudad de México, Mexico \\ ${ }^{3}$ Hospital Ángeles Lindavista, Ciudad de México, Mexico \\ ${ }^{4}$ Medical Affairs Department, Ferrer Internacional, Barcelona, Spain \\ *Author for correspondence: jruizo@ferrer.com
}

\begin{abstract}
Aim: To determine the effectiveness of Centro Nacional de Investigaciones Cardiovasculares (CNIC)polypill (acetylsalicylic acid $100 \mathrm{mg}$, ramipril $5 / 10 \mathrm{mg}$, simvastatin $40 \mathrm{mg}$ ) in achieving blood pressure (BP) goals. Patients \& methods: A multicenter, observational, one cohort, prospective study. BP targets were analyzed in patients with cardiovascular disease after 12-months treatment with the CNIC polypill. Results: A total of 572 patients ( $59.4 \pm 13.9$ years, $57.3 \%$ men) were analyzed. At baseline, BP was $147.1 \pm 18.1 / 88.3 \pm 10.6 \mathrm{mmHg}, 97.1 \%$ of patients were taken renin-angiotensin system inhibitors, $5.4 \%$ calcium antagonists, $1.9 \%$ diuretics and $13.1 \%$-blockers. The proportion of patients who achieved BP targets increased from 20.1 to $55.4 \%$ ( $p<0.001$ ). Conclusion: In routine practice, switching from usual care to the CNIC-polypill in patients with cardiovascular disease could facilitate achieving BP goals.
\end{abstract}

First draft submitted: 5 November 2019; Accepted for publication: 2 December 2019; Published online: 18 December 2019

Keywords: blood pressure $\bullet$ cardiovascular $\bullet$ hypertension $\bullet$ mild-incoming countries $\bullet$ polypill

Hypertension is the leading global contributor to premature death, ischemic heart disease and stroke [1]. It has been estimated that the overall prevalence of hypertension in adults is around $30-45 \%$. This is consistent across the world, irrespective of income status. However, the prevalence of hypertension worldwide will continue to rise owing to aging of the population, more sedentary lifestyles and the increase in overweight/obesity [2]. In Mexico, the prevalence of hypertension reaches $32 \%$ in the adult population [3], although it may be higher in elderly persons [4] and is expected to increase in the coming years [5].

Cardiovascular disease is responsible for approximately a third of global mortality [6,7]. However, whereas in some countries such as the USA or Canada, age-adjusted mortality rates due to ischemic heart disease have progressively decreased, the decline has been less marked in other regions, such as Latin America [8,9]. This is associated with poor control of cardiovascular risk factors and low adherence to some cardiovascular medications with proven efficacy $[10,11]$.

Clinical practice guidelines recommend the use of low-dose acetylsalicylic acid, angiotensin-converting enzyme inhibitors (ACEi), $\beta$-blockers and statins for secondary prevention [12]. Unfortunately, the use of these drugs in patients with cardiovascular disease is markedly insufficient. The PURE study showed that in Latin America, only $30.1 \%$ of patients with ischemic heart disease were receiving acetylsalicylic acid, $34.2 \% \beta$-blockers, $36 \%$ renin-angiotensin system blockers and $18.0 \%$ statins [13].

Guidelines indicate that combining different components into one pill ('polypill') reaches targets for control of cardiovascular risk factors [12]. The Centro Nacional de Investigaciones Cardiovasculares (CNIC) polypill, which consists of acetylsalicylic acid $100 \mathrm{mg}$, ramipril 5 or $10 \mathrm{mg}$ and simvastatin (or atorvastatin), is the first polypill to

Future Medicine 
be approved in Europe and Latin America [14,15]. Since patients included in clinical trials differ from those attended in routine practice, studies analyzing the use of cardiovascular drugs in a 'real-life' population seem mandatory [16].

SORS is the first study to evaluate the effectiveness of the CNIC polypill in patients at high cardiovascular risk in clinical practice. The results showed that this strategy was associated with improvements in blood pressure (BP) and LDL cholesterol targets, independently of baseline treatment [17]. With this post hoc analysis, we assessed whether the switch to CNIC polypill from usual care in patients with cardiovascular disease facilitates achievement of the 2016 European Society of Cardiology (ESC) guideline targets for BP under conditions of daily clinical practice.

\section{Patients \& methods}

The design of this study is addressed elsewhere [17]. Briefly, SORS was a multicenter, observational and prospective study of a single cohort of patients in Mexico who initiated treatment with the CNIC polypill for prevention of cardiovascular events based on the criteria of the attending physician. In the SORS study, men and women over 18 years or older who initiated treatment with the CNIC polypill for cardiovascular prevention at the discretion of the practitioners in clinical practice were included. Patients with contraindications to the use of the CNIC polypill (severe renal failure [creatinine clearance $<30 \mathrm{ml} / \mathrm{min}$ ], severe liver disease or severe heart failure) were excluded. If the patient was taken aspirin, statins or ACEi/angiotensin receptor blockers, these medications were withdrawn when switching to the polypill. In this post hoc analysis, only patients with established cardiovascular disease were included.

The participants comprised 140 investigators from cardiology clinics who were representative of the geographical composition of Mexico. Each practitioner was asked to consecutively include patients who started treatment with the CNIC polypill according to clinical guidelines and clinical practice. Participation in the study did not involve specific diagnostic or therapeutic procedures. Patients were followed for 12 months after enrollment and were seen after 1, 3 and 12 months. Additional visits for the clinical follow-up of patients were arranged at the discretion of the practitioners.

Sociodemographic data, cardiovascular risk factors for heart failure, atrial fibrillation and the type of cardiovascular disease were recorded at baseline. Antihypertensive drugs were also recorded at baseline and after 12 months of treatment. Changes in BP during the study, achievement of the 2016 ESC guideline targets for BP $(<140 / 90 \mathrm{mmHg}$ for the general population and $<130 / 80 \mathrm{mmHg}$ for diabetics) [12] and changes in the severity of hypertension were determined and compared at baseline and at the end of the study.

The protocol adhered to the ethical guidelines of the 1975 Declaration of Helsinki and was approved by the local health authorities prior to initiation. Patients gave their written informed consent before being included in the study.

\section{Statistical analysis}

This post hoc analysis was performed in the intention-to-treat population, defined as those patients with wellestablished cardiovascular disease who received at least one dose of the CNIC polypill and had at least one postbaseline primary end point measurement. Quantitative data were presented as measures of central tendency and dispersion (mean and standard deviation) and categorical data as absolute and relative frequencies (\%). The primary analysis of mean differences in control of BP between baseline and the end of the study was conducted using the $t$-test. Categorical variables were compared using the $\chi^{2}$ test. Stepwise binary logistic regression analysis was performed to identify those clinical variables associated with control of BP. Those variables with a $p<0.10$ in the univariate analysis were included in the multivariate analyses. Odds ratios and their respective $95 \%$ CIs were used to describe the results of the multivariate analysis. Statistical significance was set at $\mathrm{p}<0.05$. All the statistical analyses were performed using the statistical package SPSS (v22.0).

\section{Results}

From a total of 1193 patients included in the SORS study [17], 572 (47.9\%) had cardiovascular disease and were included in the analysis. Table 1 shows the demographic and clinical characteristics of the study population. Mean age was $59.4 \pm 13.9$ years, and $57.3 \%$ of patients were men. Cardiovascular risk factors were frequent, with hypercholesterolemia $(86.9 \%)$ and hypertension $(85.8 \%)$ being the most common ones.

At baseline, $92.0 \%$ of patients were receiving either ACEi or angiotensin receptor blockers, $13.1 \% \beta$-blockers, $5.4 \%$ calcium channel blockers and $1.9 \%$ diuretics. The CNIC polypill with the 5-mg dose of ramipril was used in $56.7 \%$ of patients. 


\begin{tabular}{|c|c|}
\hline Variable & Study population $(n=572 ; 100 \%)$ \\
\hline \multicolumn{2}{|l|}{ Sociodemographic data } \\
\hline Age (years) & $59.4 \pm 13.9$ \\
\hline Males, n (\%) & $328(57.3)$ \\
\hline BMI $\left(\mathrm{kg} / \mathrm{m}^{2}\right)$ & $29.6 \pm 4.6$ \\
\hline $\begin{array}{l}\text { Race, } \mathrm{n}(\%) \\
\text { - Hispanic Amerindian } \\
\text { - White } \\
\text { - Black } \\
\text { - Indigenous } \\
\text { - Other }\end{array}$ & $\begin{array}{l}252(47.6) \\
238(45.0) \\
6(1.1) \\
5(0.9) \\
28(5.3)\end{array}$ \\
\hline $\begin{array}{l}\text { Area of residence, } n(\%) \\
\text { - Urban } \\
\text { - Rural }\end{array}$ & $\begin{array}{l}488(87.1) \\
72(12.9)\end{array}$ \\
\hline $\begin{array}{l}\text { Level of education, } n(\%) \\
\text { - Primary education } \\
\text { - Secondary education } \\
\text { - University degree } \\
\text { - Highly educated } \\
\text { - Illiterate }\end{array}$ & $\begin{array}{l}198(37.7) \\
139(26.5) \\
77(14.7) \\
65(12.4) \\
46(8.8)\end{array}$ \\
\hline \multicolumn{2}{|l|}{ CV risk factors/CVD } \\
\hline Hypercholesterolemia, n (\%) & $497(86.9)$ \\
\hline Arterial hypertension, n (\%) & $491(85.8)$ \\
\hline Hypertriglyceridemia, n (\%) & $329(57.5)$ \\
\hline Familial history of CVD, n (\%) & $276(50.1)$ \\
\hline Obesity, n (\%) & $243(42.7)$ \\
\hline Diabetes mellitus, n (\%) & $178(31.1)$ \\
\hline $\begin{array}{l}\text { Smoking, n (\%) } \\
\text { - Smokers } \\
\text { - Former smokers }\end{array}$ & $\begin{array}{l}115(20.1) \\
105(18.4)\end{array}$ \\
\hline Heart failure, n (\%) & $30(5.2)$ \\
\hline Atrial fibrillation, n (\%) & $14(2.4)$ \\
\hline $\begin{array}{l}\text { Cardiovascular disease } \\
\text { - Ischemic heart disease } \\
\text { - Stable angina } \\
\text { - Acute myocardial infarction } \\
\text { - Unstable angina } \\
\text { - Myocardial revascularization } \\
\text { - Cerebrovascular disease } \\
\text { - Hypertensive heart disease }\end{array}$ & $\begin{array}{l}572(100) \\
552(96.5) \\
263(46.0) \\
216(37.8) \\
70(12.2) \\
3(0.5) \\
19(3.3) \\
1(0.2)\end{array}$ \\
\hline \multicolumn{2}{|l|}{ Antihypertensive drugs, n (\%) } \\
\hline $\begin{array}{l}\text { - Patients treated with ACEi/ARB } \\
\text { - ACEi } \\
\text { - ARB } \\
\text { - Calcium antagonists } \\
\text { - Diuretics } \\
\text { - } \beta \text {-blockers }\end{array}$ & $\begin{array}{l}527(92.1) \\
512(89.5) \\
15(2.6) \\
31(5.4) \\
11(1.9) \\
75(13.1)\end{array}$ \\
\hline
\end{tabular}

The proportion of patients who achieved adequate control of BP increased significantly from 20.1 to $55.4 \%$ $(p<0.001)$. Control of BP was independent of the use of concomitant antihypertensive treatment during the study $(53.3 \%$ in the group with polypill alone vs $55.5 \%$ in the polypill plus other antihypertensive drugs, $\mathrm{p}=0.48$ ) (Figure 1). BP measures decreased significantly and progressively during the 1-year study (Figure 2). After 12 months of treatment with the CNIC polypill, a significantly lower number of patients required $\beta$-blockers, although there was no significant change in the prescription of calcium channel blockers or diuretics (Figure 3). Therefore, we cannot rule out that a more aggressive strategy based on a therapy with polypill and other additional antihypertensives in most patients would have shown greater control of blood pressure. Figure 4 shows the proportion of patients in whom the severity of hypertension varied during the course of the study. All in all, the severity of hypertension was also decreased with the polypill. 


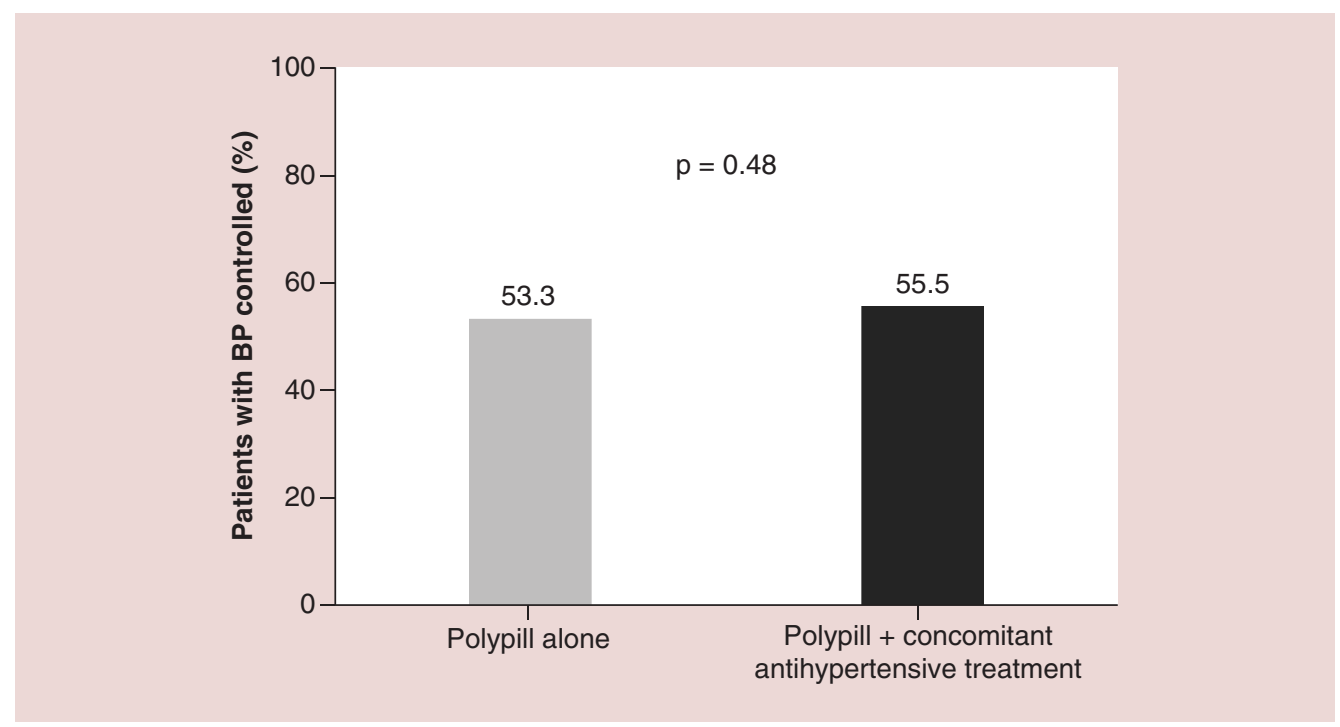

Figure 1. Control of blood pressure at month 12 with or without concomitant treatment to the Centro Nacional de Investigaciones Cardiovasculares polypill.

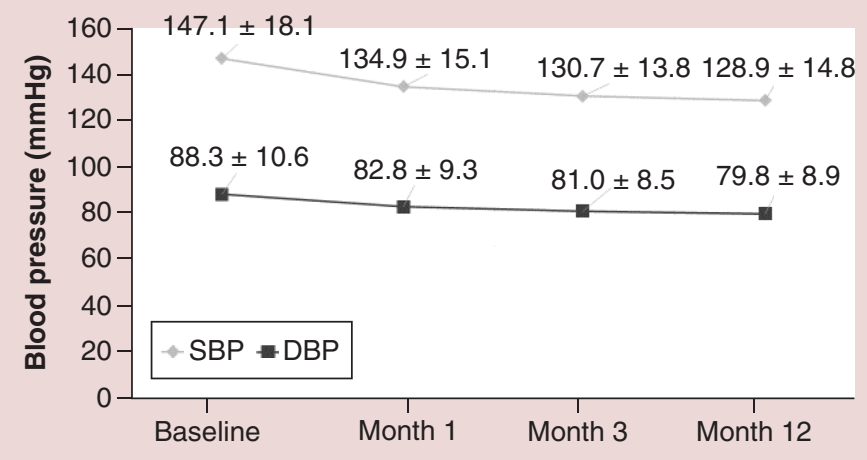

Figure 2. Changes in systolic and diastolic blood pressure over 12 months of treatment with the Centro Nacional de Investigaciones Cardiovasculares polypill.

DBP: Diastolic blood pressure; SBP: Systolic blood pressure.

Finally, obesity, BP controlled at baseline and female sex were the factors associated with good control of BP at 12 months, whereas carrying out household activities and diabetes were associated with poor control of BP at 12 months (Table 2).

\section{Discussion}

This subanalysis showed that switching from usual care to a polypill strategy could facilitate achieving the 2016 ESC guideline targets for BP in a real-life setting of patients with cardiovascular disease, as a result of the better control of BP observed in the original SORS study [17]. According to the ESC guidelines, achievement of the BP target (SBP $<140 \mathrm{mmHg}$ and DBP $<90 \mathrm{mmHg}$ in all treated hypertensive patients $<60$ years old, with slight differences depending on age and clinical condition) is essential for prevention of cardiovascular disease in clinical practice [12]. Consequently, it is very discouraging that, at baseline, only $20 \%$ of patients had well-controlled BP, even though all of them had cardiovascular disease. This proportion is much worse that that observed in other studies (60\%), which has already been established as poor [18-20]. Our results are probably a consequence of the geographical area where the study was carried out. The former studies were performed in high-income areas, whereas ours was 


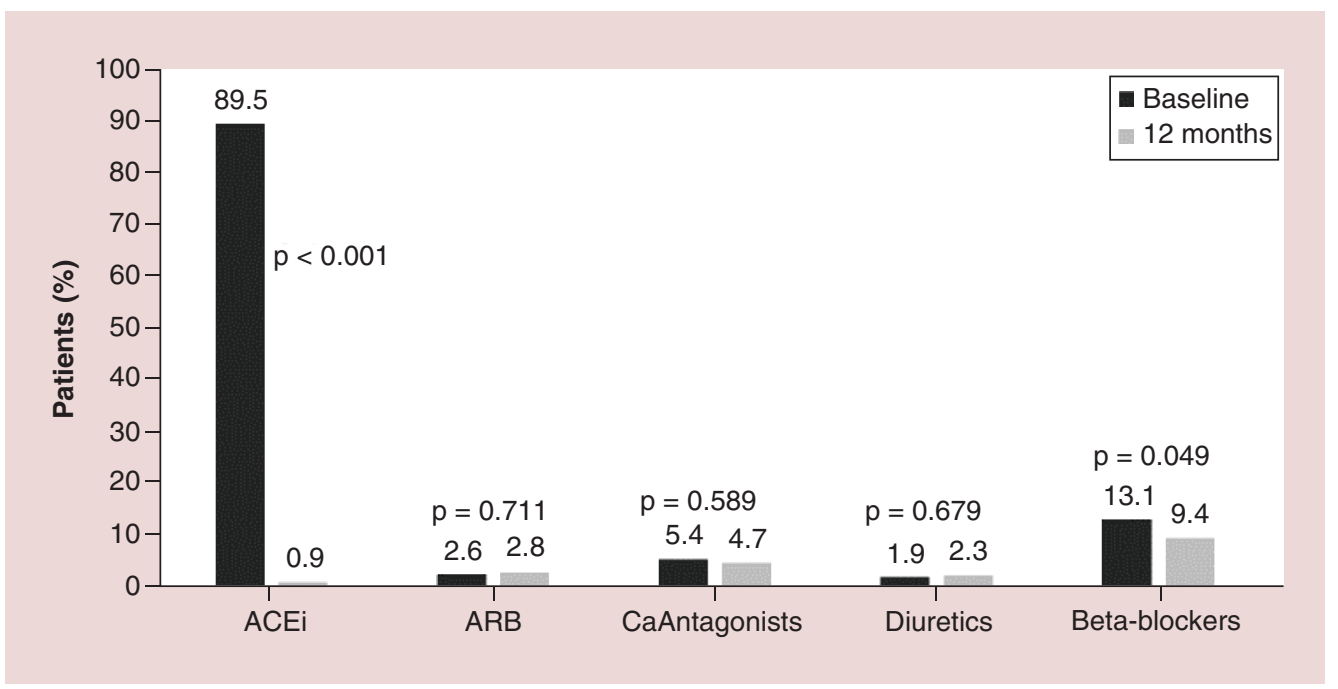

Figure 3. Concomitant use of antihypertensive drugs.

ACEi: Angiotensin-converting enzyme inhibitor; ARB: Angiotensin receptor blocker; CaAntagonist: Calcium antagonist.

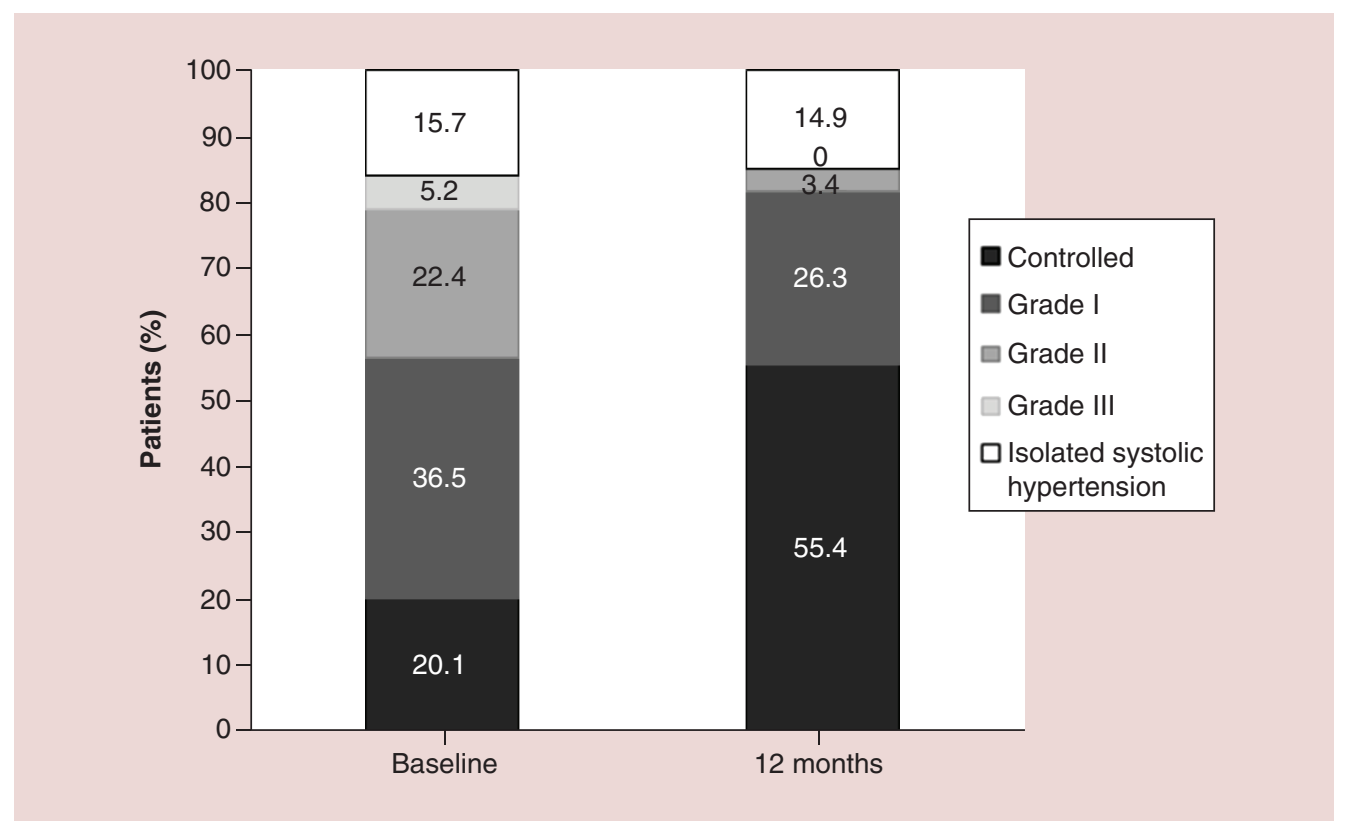

Figure 4. Shift in the grade of hypertension with the Centro Nacional de Investigaciones Cardiovasculares polypill during the study.

performed in Mexico, an upper middle-income country. It is broadly demonstrated that rates of cardiovascular drug use decrease with declining national economic wealth, and in rural areas compared with urban sites, owing to restricted availability of drugs, inconvenience, costs associated with visiting physicians and absence of systematic programs for long-term preventive care [13]. Our percentages are also lower than those from other epidemiologic studies performed in Mexico, which reported that $50 \%$ of patients did not have well-controlled BP, most likely owing to the different methodologies used [3]. In any case, urgent efforts must be made to understand the reasons for these low success rates, to establish systematic preventive programs, and to increase the use of effective drugs for prevention of cardiovascular disease. 


\begin{tabular}{|c|c|c|c|c|}
\hline \multirow[t]{2}{*}{ Variable } & \multirow[t]{2}{*}{$\operatorname{Exp}(B)$} & \multicolumn{2}{|c|}{ 95\% Cl for $\operatorname{Exp}(\mathrm{B})$} & \multirow[t]{2}{*}{ p-value } \\
\hline & & Lower & Upper & \\
\hline Obesity & 2.337 & 1.393 & 3.922 & 0.001 \\
\hline BP controlled at baseline & 2.213 & 1.096 & 4.469 & 0.027 \\
\hline Females & 1.861 & 1.098 & 3.153 & 0.021 \\
\hline Household activities & 0.392 & 0.171 & 0.901 & 0.027 \\
\hline Diabetes & 0.090 & 0.051 & 0.158 & 0.000 \\
\hline Former smoker & 1.875 & 0.918 & 3.828 & 0.084 \\
\hline Smoker & 1.506 & 0.789 & 2.871 & 0.214 \\
\hline Age ( $>60$ years) & 1.104 & 0.662 & 1.841 & 0.704 \\
\hline Excessive alcohol consumption & 1.066 & 0.558 & 2.036 & 0.848 \\
\hline Familiar history of CVD & 0.711 & 0.435 & 1.163 & 0.174 \\
\hline Good eating habits & 0.686 & 0.410 & 1.147 & 0.151 \\
\hline Physical inactivity & 0.556 & 0.250 & 1.237 & 0.150 \\
\hline Constant & 2.620 & - & - & 0.038 \\
\hline
\end{tabular}

A polypill-based strategy could facilitate prevention of cardiovascular disease by improving the control of risk factors. Thus, various randomized clinical trials that have analyzed the effects of a polypill strategy on control of risk factors compared with usual care generally showed that the polypill approach improves control of cardiovascular risk factors [15,18-20]. The SPACE collaboration, for example, performed an individual meta-analysis of three randomized clinical trials comparing a strategy using a polypill containing aspirin, a statin and antihypertensive therapy with usual care in patients with cardiovascular diseases and demonstrated that this strategy significantly facilitates achievement of ESC targets for BP, LDL and antiplatelet therapy, particularly in undertreated patients [20]. A recent study has also shown that a polypill strategy could also reduce the incidence of cardiovascular events [21]. An increase in the number of fully-adherent patients to cardiovascular therapy was one of the factors related to this improvement. Moreover, the FOCUS study, the first trial to specifically study the effect of the CNIC polypill strategy on adherence in secondary prevention, showed a significant improvement from $41 \%$ in participants taking individual medications to $51 \%$ in the polypill group [15].

We also observed a significant improvement in the proportion of patients who met the recommended BP target (from 20.1 to $55.4 \%$ ), which was similar to that reported in other clinical trials. Of note, in general, due to the main inclusion criterion (patients in whom the physician considered it appropriate to substitute statin, ACEi and aspirin for the CNIC polypill), the number of patients taking dual therapy for BP control at baseline was low. However, the results between different studies were not comparable because of differences in the methodologies used. Although the adherence was not measured in our case, it seems logical that the simplification of treatment could have had a positive impact on the achievement of target BP levels. The use of a polypill is in line with current guidelines. Thus, 2017 ACC/AHA hypertension guidelines recommend that adults with stable ischemic heart disease and hypertension should be treated with medications ( $\beta$-blockers, ACEi or angiotensin receptor blockers) for compelling indications as first-line therapy, with the addition of other as needed to further control hypertension. In patients in which the CNIC polypill is not enough to achieve BP targets, additional medications could be added [22].

The present study had several limitations. First, it was a post hoc analysis of data from the SORS study and was therefore hypothesis-generating in nature. The original study was not performed with this objective, and the number of patients to be included in the subanalysis was not previously calculated. Second, since data were recorded at clinics, they are not representative of the overall Mexican population, in which there are important differences between primary and specialized care and between rural and urban areas [3,4]. Third, the method of measuring BP was not standardized, as appropriate for daily clinical practice in each institution, thus rendering comparison of baseline and final BP values less accurate. Fourth, the aim of the study was to describe the implementation of a therapeutic strategy with a polypill in Mexico and to describe its effectiveness on risk factors, but not specifically reaching BP control. Therefore, the results could have been different, presumably greater, if the objective had been 
the strict control of BP with an established strategy in polypill and in the appropriate additional medications until reaching goals.

A major strength of this subanalysis lies in the observational nature of the original study. As far we know, SORS is the first study to evaluate the effectiveness of a polypill in the prevention of cardiovascular disease under clinical practice conditions. It has been suggested that patients who participate in a randomized clinical trial could change their behavior artificially in response to their awareness of being observed, for example, in relation to adherence, thus reducing the robustness of the results [23]. Therefore, we consider that polypill-based strategies should be evaluated under conditions of daily clinical practice.

\section{Conclusion}

Switching from usual care to the CNIC polypill in patients with cardiovascular disease could help to reach the BP goals. Such an approach may improve prevention of cardiovascular disease.

\section{Summary points}

- SORS has been the first study to evaluate the effectiveness of the Centro Nacional de Investigaciones Cardiovasculares (CNIC) polypill in patients at high cardiovascular risk in clinical practice until data.

- The main results of the study SORS showed that CNIC polypill is effective and safe in real clinical conditions.

- We performed a subanalysis of the study SORS to determine the effectiveness of the CNIC polypill for achievement of the 2016 European Society of Cardiology targets for blood pressure.

- Our results showed that in routine practice, switching from usual care to the CNIC polypill in patients with cardiovascular disease could facilitate achievement of the 2016 European Society of Cardiology targets for blood pressure.

- Our results are in agreement with previous studies, stablishing that polypill is a good strategy that could improve the goals of cardiovascular prevention.

\section{Acknowledgments}

The authors would like to thank JL Lorenzo, employee of Ferrer, who helped editing the manuscript.

\section{Financial \& competing interests disclosure}

ER is an employee of Ferrer Internacional. The authors have no other relevant affiliations or financial involvement with any organization or entity with a financial interest in or financial conflict with the subject matter or materials discussed in the manuscript. This includes employment, consultancies, honoraria, stock ownership or options, expert testimony, grants or patents received or pending, or royalties. The medical writing support was provided by Content Ed Net (Madrid, Spain) and was funded by Ferrer Internacional SA.

\section{Open access}

This work is licensed under the Attribution-NonCommercial-NoDerivatives 4.0 Unported License. To view a copy of this license, visit http://creativecommons.org/licenses/by-nc-nd/4.0/

\section{References}

Papers of special note have been highlighted as: $\bullet$ of interest; $\bullet \bullet$ of considerable interest

1. Forouzanfar MH, Liu P, Roth GA et al. Global burden of hypertension and systolic blood pressure of at least 110 to $115 \mathrm{~mm} \mathrm{Hg}$ 1990-2015. JAMA 317(2), 165-182 (2017).

2. Chow CK, Teo KK, Rangarajan S et al. Prevalence, awareness, treatment, and control of hypertension in rural and urban communities in high-, middle-, and low-income countries. JAMA 310(9), 959-968 (2013).

3. Campos-Nonato I, Hernandez-Barrera L, Rojas-Martınez R et al. Hypertension: prevalence, early diagnosis, control and trends in Mexican adults. Salud. Publica. Mex. 55(Suppl. 2), S144-S150 (2013).

- The study by Campos Nonato et al., showed the high prevalence of hypertension in Mexico and the low level of control.

4. Garcia-Peña C, Thorogood M, Reyes $S$ et al. The prevalence and treatment of hypertension in the elderly population of the Mexican Institute of Social Security. Salud. Publica. Mex. 43(5), 415-420 (2001).

5. Ruilope LM, Nunes Filho ACB, NadruzWJr et al.Obesity and hypertension in Latin America: current perspectives. Hipertens. Riesgo. Vasc. 35(2), 70-76 (2018). 
6. Sosa-Liprandi Á, Sosa Liprandi MI, Alexánderson E et al. Clinical impact of the polypill for cardiovascular prevention in Latin America: a consensus statement of the Inter-American Society of Cardiology. Glob. Heart 14(1), 3-16 (2019).

7. Benjamin EJ, Muntner P, Alonso A et al. Heart disease and stroke statistics-2019 update: a report from the American Heart Association. Circulation 139(10), e56-e66 (2019).

8. Rodriguez T, Malvezzi M, Chatenoud L et al. Trends in mortality from coronary heart and cerebrovascular diseases in the Americas: 1970-2000. Heart 92(4), 453-460 (2006).

9. Fernando L, Pamela S, Alejandra L. Cardiovascular disease in Latin America: the growing epidemic. Prog. Cardiovasc. Dis. 57(3), 262-267 (2014).

10. Fleischer NL, Diez Roux AV. Inequities in cardiovascular diseases in Latin America. Rev. Peru. Med. Exp. Salud. Publica. 30(4), 641-648 (2013).

11. Ruilope LM, Chagas AC, Brandão AA et al. Hypertension in Latin America: current perspectives on trends and characteristics. Hipertens. Riesgo. Vasc. 34(1), 50-56 (2017).

12. Piepoli MF, Hoes AW, Agewall S et al. 2016 European Guidelines on cardiovascular disease prevention in clinical practice: the sixth joint task force of the European Society of cardiology and other societies on cardiovascular disease prevention in clinical practice. Eur. Heart J. 37(29), 2315-2381 (2016).

13. Avezum A, Oliveira GBF, Lanas F et al. Secondary CV prevention in South America in a community setting: the PURE study. Glob. Heart 12(4), 305-313 (2017).

- Shows the low level of guideline-drive treatments in secondary patients in Latin America.

14. Barrios V, Escobar C. Improving cardiovascular protection: focus on a cardiovascular polypill. Future Cardiol. 12(2), 181-196 (2016).

15. Castellano JM, Sanz G, Peñalvo JL et al. A polypill strategy to improve adherence: results from the FOCUS project. J. Am. Coll. Cardiol. 64(20), 2071-2082 (2014).

- The FOCUS study showed that the Centro Nacional de Investigaciones Cardiovasculares polypill increased the number of adherent patients to treatment.

16. Kim HS, Lee S, Kim JH. Real-world evidence versus randomized controlled trial: clinical research based on electronic medical records. J. Korean Med. Sci. 33(34), e213 (2018).

17. Castellano J, Verdejo J, Ocampo S. Clinical effectiveness of the cardiovascular polypill in a real-life setting in patients with cardiovascular risk in Mexico: the SORS study. Arch. Med. Res. 50(1), 31-40 (2019).

-. The present study is a post hoc analysis of the SORS study, which showed for the first time that a polypill improved risk factor additional to usual care.

18. Kotseva K, Wood D, De Bacquer D et al. EUROASPIRE IV: a European Society of Cardiology survey on the lifestyle, risk factor and therapeutic management of coronary patients from 24 European countries. Eur. J. Prev. Cardiol. 23(6), 636-648 (2016).

19. Cooney M, Reiner Z, Sheu W et al. SURF - SUrvey of Risk Factor management: first report of an international audit. Eur. J. Prev. Cardiol. 21(7), 813-822 (2014).

20. Selak V, Webster R, Stepien S et al. Reaching cardiovascular prevention guideline targets with a polypill-based approach: a meta-analysis of randomised clinical trials. Heart 105(1), 42-48 (2019).

-. The metaanalysis by Selak et al., clearly demonstrated that a polypill increase the number of patients achieving goals for LDL-cholesterol and blood pressure in a clinical trial setting.

21. Roshandel G, Khoshnia M, Poustchi $\mathrm{H}$ et al. Effectiveness of polypill for primary and secondary prevention of cardiovascular diseases (PolyIran): a pragmatic, cluster-randomised trial. Lancet 394(10199), 672-683 (2019).

-. The Polyiran study is the first clinical trial to demonstrated that a polypill-based strategy improved the incidence of cardiovascular events.

22. Whelton PK, Carey RM, Aronow WS, Casey DE Jr, Collins KJ, Dennison Himmelfarb C et al. 2017 ACC/AHA/AAPA/ABC/ACPM/AGS/APhA/ASH/ASPC/NMA/PCNA guideline for the prevention, detection, evaluation, and management of high blood pressure in adults: executive summary: a report of the American College of Cardiology/American Heart Association Task Force on Clinical Practice Guidelines. Circulation 138(17), e426-e483 (2018).

23. Fernald DH, Coombs L, DeAlleaume L et al. An assessment of the hawthorne effect in practice-based research. J. Am. Board. Fam. Med. 25(1), 83-86 (2012). 